\title{
The relationship between trauma and idiopathic torsion dystonia
}

\author{
N A Fletcher, A E Harding, C D Marsden
}

\begin{abstract}
Generalised, multifocal or segmental idiopathic torsion dystonia (ITD), is caused by an autosomal dominant gene with reduced penetrance in about $85 \%$ of cases. Of 104 patients with these types of ITD, $17(16.4 \%)$ gave a history which suggested that dystonic movements had been precipitated or exacerbated by trauma. Eight of these 17 patients had affected relatives. If precipitated, dystonia appeared first in the injured part of the body within days or up to 12 months after the trauma and later became more widespread. Peripheral injuries may influence basal ganglia function and provoke the onset of dystonic movements in individuals who are ITD gene carriers.
\end{abstract}

Idiopathic torsion dystonia (ITD) is characterised by dystonic movements and postures in the absence of other neurological deficits, or an identified underlying cause such as Wilson's disease and other metabolic or degenerative diseases, encephalitis, neonatal hypoxic-ischaemic encephalopathy or exposure to neuroleptic drugs. ${ }^{1}$ In the United Kingdom, about $85 \%$ of cases of generalised or segmental ITD are probably caused by a single autosomal dominant gene with $40 \%$ penetrance and highly variable expression. ${ }^{2}$ The phenotype of autosomal dominant ITD ranges from severe childhood onset generalised disease to mild adult onset focal dystonia or postural tremor. Many solitary cases are probably due to new mutations or inheritance of the ITD gene from an asymptomatic gene carrier parent. Negligible intrafamilial correlations for both age of onset and severity of involuntary movements are consistent with the hypothesis that the highly variable clinical features of ITD are determined by interaction of environmental factors with the ITD gene, rather than modification by other genes or genetic heterogeneity. ${ }^{2}$

The nature of environmental factors modifying the ITD phenotype is unknown. Trauma is a possible candidate, as several reports of dystonia precipitated by peripheral injuries have accumulated. ${ }^{3}$ Such patients are distinct from cases of dystonia following head injury complicated by damage to the basal ganglia. ${ }^{45}$ Direct basal ganglia damage cannot be the explanation for the development of dystonia when the trauma is strictly peripheral and localised. In this study, the relationship between trauma and dystonia was examined in a large series of cases of generalised, multifocal and segmental ITD, in the majority of which there was evidence for a diagnosis of inherited dystonia. ${ }^{2}$ The aim was to establish how often trauma appears to precipitate dystonia in those who are at risk of developing it by virtue of being ITD gene carriers.

\section{Methods}

All patients were seen as part of a clinical and genetic study of generalised, multifocal or segmental ITD in the UK. ${ }^{2}$ They were all interviewed and examined according to a standardised protocol by one of us (NAF) in 1987 and 1988. Diagnostic criteria for ITD were: 1) generalised, multifocal or segmental dystonia as defined by Fahn et al; ${ }^{5}$ 2) no pyramidal, cerebellar, sensory or intellectual deficit; 3) no history of perinatal hypoxicischaemic encephalopathy or kernicterus and normal early development; 4) no other predisposing cause for secondary dystonia such as encephalitis or neuroleptic drug exposure; 5) no cause disclosed by investigation, particularly imaging and laboratory investigations and 6) no clinical features to suggest secondary dystonia or other dystonic states of unknown aetiology such as dopa responsive, paroxysmal or alcohol responsive myoclonic dystonia. ${ }^{6}$ Ascertainment was not biased in favour of familial cases; those referred specifically because of a positive family history were not included.

In all patients who participated, a medical and family history was taken, including details about previous injuries and surgical or dental procedures (excluding simple fillings or single extractions) and complete neurological examinations were performed. To minimise heterogeneity, cases with only focal dystonia or in which the diagnosis of ITD was not secure were excluded.

\section{Results}

One hundred and four patients fulfilled the inclusion criteria for this study. ${ }^{2}$ Dystonia was generalised in $51(49.0 \%)$, multifocal in seven $(6.7 \%)$, segmental in $45(43.3 \%)$ and one had idiopathic hemidystonia. Of the 45 segmental cases, 25 had axial, nine cranial, nine brachial and two crural segmental dystonia. Fifty five $(54 \%)$ had relatives with dystonia.

Twenty one of the 104 patients dated the onset of their dystonia to an episode of trauma, 
Table Patients with dystonia probably precipitated or exacerbated by peripheral injury

\begin{tabular}{|c|c|c|c|c|c|c|}
\hline Case & $F H$ & $\begin{array}{l}\text { Age at } \\
\text { injury (years) }\end{array}$ & $\begin{array}{l}\text { Nature of } \\
\text { injury }\end{array}$ & $\begin{array}{l}\text { Site of } \\
\text { onset }\end{array}$ & Interval & $\begin{array}{l}\text { Current } \\
\text { extent }\end{array}$ \\
\hline \multicolumn{7}{|c|}{ Group I: Dystonia precipitated by trauma } \\
\hline $\begin{array}{r}1 \\
2 \\
3 \\
4 \\
5 \\
6 \\
7 \\
8 \\
9 \\
10 \\
11 \\
12 \\
13 \\
14\end{array}$ & $\begin{array}{l}\mathbf{Y} \\
\mathbf{Y} \\
\mathbf{Y} \\
\mathbf{Y} \\
\mathbf{N} \\
\mathbf{Y} \\
\mathbf{Y} \\
\mathbf{Y} \\
\mathbf{N} \\
\mathbf{N} \\
\mathbf{N} \\
\mathbf{N} \\
\mathbf{Y} \\
\mathbf{N}\end{array}$ & $\begin{array}{r}35 \\
15 \\
13 \\
7 \\
5 \\
20 \\
6 \\
50 \\
47 \\
40 \\
59 \\
15 \\
17 \\
7\end{array}$ & $\begin{array}{l}\text { Surgery (dental) } \\
\text { Surgery (dental) } \\
\text { Laceration (hand) } \\
\text { Venous cannula } \\
\text { Sprain (arm) } \\
\text { Sprain (ankle) } \\
\text { Laceration (leg) } \\
\text { Head injury } \\
\text { Sprain (neck) } \\
\text { Contusion (trunk) } \\
\text { Surgery (dental) } \\
\text { Contusion (hand) } \\
\text { Fracture (nasal) } \\
\text { Contusion (face) }\end{array}$ & $\begin{array}{l}\text { OMD } \\
\text { OMD } \\
\text { WC } \\
\text { Arm } \\
\text { Arm } \\
\text { Foot } \\
\text { Foot } \\
\text { Neck } \\
\text { Neck } \\
\text { Neck } \\
\text { BS } \\
\text { Hand } \\
\text { OMD } \\
\text { SD }\end{array}$ & $\begin{array}{l}\text { < } 1 \text { year } \\
<1 \text { month } \\
<1 \text { month } \\
\text { Immediate } \\
\text { Immediate } \\
<1 \text { week } \\
<1 \text { year } \\
<1 \text { month } \\
6 \text { weeks } \\
1 \text { day } \\
<1 \text { year } \\
<3 \text { months } \\
6 \text { months } \\
\text { < } 1 \text { month }\end{array}$ & $\begin{array}{l}\text { Axial (S) } \\
\text { Generalised } \\
\text { Generalised } \\
\text { Generalised } \\
\text { Generalised } \\
\text { Generalised } \\
\text { Multifocal } \\
\text { Axial (S) } \\
\text { Axial (S) } \\
\text { Axial (S) } \\
\text { Cranial (S) } \\
\text { Hemi } \\
\text { Generalised } \\
\text { Generalised }\end{array}$ \\
\hline \multicolumn{7}{|c|}{ Group II: Dystonia exacerbated by trauma } \\
\hline $\begin{array}{r}3 \\
4 \\
15 \\
16\end{array}$ & $\begin{array}{l}\mathbf{Y} \\
\mathbf{Y} \\
\mathbf{N} \\
\mathbf{N} \\
\mathbf{N}\end{array}$ & $\begin{array}{r}34 \\
8 \\
27 \\
5 \\
29 \\
10\end{array}$ & $\begin{array}{l}\text { Surgery (spinal) } \\
\text { Fracture (arm) } \\
\text { Sprain (lumbar) } \\
\text { Electrical (trunk) } \\
\text { Surgery (leg) } \\
\text { Fracture (arm) }\end{array}$ & $\begin{array}{l}\text { Axial } \\
\text { Arm } \\
\text { Axial } \\
\text { Axial } \\
\text { Leg } \\
\text { Arm }\end{array}$ & $\begin{array}{l}2 \text { days } \\
6 \text { weeks } \\
2 \text { weeks } \\
\text { Immediate } \\
\text { Immediate } \\
\text { Immediate }\end{array}$ & $\begin{array}{l}\text { Generalised } \\
\text { Generalised } \\
\text { Generalised } \\
\text { Generalised } \\
\text { Generalised }\end{array}$ \\
\hline
\end{tabular}

$\mathrm{SD}=$ spasmodic dysphonia; $(\mathbf{S})=$ segmental; $\mathrm{FH}=$ family history $; \mathrm{Y}=$ yes; $\mathrm{N}=$ no.

either an injury or a surgical procedure, three reported striking exacerbation of existing dystonia after an injury or surgery, and two reported both of these phenomena. These 26 cases were grouped into the following categories: 1) Onset possibly precipitated by trauma (trauma followed by the onset of dystonia in the same region within one year); 2) Existing dystonia exacerbated by trauma within two months; 3) Reports of uncertain significance (dystonia following injury after a long delay or to a remote site); 4) Trauma which probably followed the onset of the dystonia.

The relationship of trauma to onset or exacerbation in the first two groups is shown in the table; in two (cases 3 and 4) dystonia was first precipitated and later exacerbated by trauma. Therefore, $17 / 104(16.4 \%)$ index cases had a history of injury less than one year before onset or exacerbation of their dystonia, and involving the subsequently affected site.

Onset possibly precipitated by trauma

Case 1 had a difficult and painful extraction of retained roots of a tooth; this was followed within one year by oromandibular involuntary movements and subsequently by severe axial dystonia.

Case 2 had two upper molars extracted and a plate fitted. A few weeks later he developed oromandibular dystonia which progressed to generalised ITD.

Case 3 sustained a deep laceration to her right hand at the age of 13 . Writer's cramp appeared in the hand a few weeks later. At the age of 34, a laminectomy was performed for a prolapsed intervertebral disc. Severe involuntary movements of the trunk appeared postoperatively and have persisted.

Case 4 had a laparotomy for peritonitis and an intravenous cannula was inserted into the left forearm; her mother noted involuntary movements of this arm while she was recovering from the anaesthetic. A year later severe involuntary movements developed in the other arm upon removal of a plaster cast after fracture of the wrist.

Case 5 fell and injured his right arm at the age of five; the arm was immobilised in a sling. Abnormal involuntary movements and postures of the arm were noted immediately and these progressed to severe dystonia of the arm and hand. He now has generalised ITD.

Case 6 fell and injured her left ankle at the age of 20. A few days later, the foot suddenly developed a dystonic posture; violent involuntary movements of the leg, especially on walking, have persisted.

Case 7 fell and sustained a deep laceration to the anterior aspect of the left leg, between the ankle and the knee. Eleven months later, she developed dystonia of the left foot and leg which progressed to severe generalised dystonia which confined her to a wheelchair.

Case 8 was struck on the head by a heavy box. There was no loss of consciousness. A few weeks later she developed torticollis and now has axial segmental dystonia.

Case 9 turned his head suddenly and awkwardly while driving in order to avoid an accident. There was a sudden pain in the neck which radiated into the back of the head. Six weeks later he developed persistent torticollis and a tremor of the hands.

Case 10 was injured between the scapulae while unloading a lorry whose heavy rear door swung closed and struck him. There was some bruising and much pain on movement, followed within 24 hours by torticollis. He now has axial segmental dystonia with involvement of trunk, arms and face.

Case 11 had a complete dental clearance for caries. This was followed after a few months by oromandibular and subsequently by cranial segmental dystonia.

Case 12 accidentally struck his left thumb with a hammer, producing bruising and swelling. A few days later the hand adopted an odd posture. This persisted and within a few weeks the left foot was also involved. Over the course of the next 10 years, further dystonia has appeared on the left side. Despite intensive neuroradiological studies, no structural lesion has been detected to account for the hemidystonia.

Case 13 fell from a bicycle at the age of 17 and sustained grazes to the face and a nasal fracture. Six months later she developed dystonic dysphonia and now has generalised ITD with prominent cranial involvement.

Case 14 fell and sustained bruising of the face. Dysphonia appeared within a few weeks followed by oromandibular dystonia; the patient now has generalised dystonia.

\section{Existing dystonia exacerbated by trauma}

In addition to cases 3 and 4 described above, who had dystonia precipitated and exacerbated by injuries, there were three other cases in whom dystonia was exacerbated by trauma. Case 15 developed dystonia of the left leg in childhood which remitted in his late teens. The involuntary movements of the leg reappeared at the age of 20 and over the next seven years spread to the arms and the other leg. At the 
age of 27, he was lifting a heavy weight at work and suddenly developed lower back pain; two weeks later, persistent involuntary movements of the trunk appeared.

Case 16 developed severe generalised dystonia at the age of three years, initially in the right leg. Two years after the onset he was given electrotherapy by a chiropractor. An unexpected surge of current produced a sudden painful contraction of the right paraspinal muscles. The resultant scoliosis persisted and severe muscle spasms of the trunk have occurred ever since. Several years later, at the age of 29 , a tendon shortening operation was performed on the right knee to correct a flexion deformity. The limb had been severely dystonic but the involuntary movements had been almost abolished by a left thalamotomy (his third) a year previously. Immediately after the tendon surgery, violent involuntary movements returned in the right leg and these have persisted.

Case 17 developed right sided writer's cramp at the age of nine and later, dystonia of the right leg and foot. A year later she fell over and fractured the left wrist. Involuntary pronation and elevation of the left arm appeared almost immediately and have persisted.

Eight of these 17 patients (cases 1, 2, 3, 4, 6, $7,8,13$ ) had relatives with dystonia.

\section{Reports of uncertain significance}

There were five cases in which the relationship between the trauma and dystonia was less clear. Case 18 developed writer's cramp eight years after an extensive laceration of the right hand. Case 19 developed torticollis 10 years after a neck injury sustained while playing rugby. There were few details about this injury but there was considerable pain and a cervical disc lesion was diagnosed at the time. At the age of nine years, case 20 sustained a laceration over the right eye which was sutured but later became infected, taking several weeks to heal. Dystonia developed in the left arm a few months later. Case 21 had a total dental clearance for pyorrhoea at the age of 30 years and poorly fitting dentures were worn subsequently; oromandibular dystonia developed 25 years later and this has progressed to cranial segmental dystonia and postural tremor. Case 22 sustained a head injury at the age of five which produced concussion. Less than one year later, dystonia developed in the left hand and rapidly became generalised. One of these five patients (case 20) had affected relatives.

Cases in which trauma was probably a consequence of early dystonia

Case 23 developed stiffness and pain in the neck at the age of 47. Traction was applied and the neck was manipulated under general anaesthesia. Obvious torticollis was noticed a few weeks later. Case 24 had boxed in over 300 bouts but had never been knocked out or seriously injured; 18 months after stopping fighting, he developed pain in the neck. After a course of neck traction he suddenly developed retrocollis and dystonia of the right arm and trunk as well as blepharospasm and dysarthria.
Case 25 suddenly "went over" on her right ankle at the age of ten and thereafter noted abnormal postures of the right foot which was remembered as being inverted and plantar flexed. She later developed severe generalised ITD. Case 26 fell because her right foot "turned in" causing her to lose balance. The foot retained a plantar flexed and inverted posture and generalised ITD has now developed. Two of these patients (cases 25 and 26) had affected relatives.

\section{Discussion}

This study was undertaken on a well defined population of patients with ITD, $85 \%$ of whom can be considered to have a genetic disorder, ${ }^{2}$ and suggests that trauma may interact with genetic susceptibility in the development of dystonia. The first 17 cases described add to the increasing and longstanding body of evidence which incriminates peripheral trauma in the onset or exacerbation of involuntary movements in various dystonic disorders, and indicate that trauma may be relevant to generalised inherited disease as well as focal dystonias which probably have a more diverse aetiology. Gowers ${ }^{7}$ described torticollis and writer's cramp after local injuries and Wilson ${ }^{8}$ referred to injury as a precipitant of "occupational cramps". Sheehy and Marsden" described three trauma-induced cases out of a series of 60 patients with torticollis and calculated that $9 \%$ of 414 cases of this focal dystonia had suffered preceding injuries. These authors ${ }^{10}$ also noted that writer's cramp could be precipitated by local hand injury, and subsequently identified five such cases amongst 91 patients. ${ }^{11}$ Marsden et $a l^{12}$ described five patients with muscle spasms and Sudeck's atrophy after injuries to a limb. Severe pain after the injury was characteristic and the movements were often dystonic in nature. Schott ${ }^{13}$ described four patients with axial or arm dystonia after local trauma, and later $^{14}$ described a further ten patients with movement disorders which appeared to have been precipitated by peripheral trauma; six of these had developed dystonia, including writer's and pianist's cramps, cranial segmental dystonia, axial segmental dystonia and focal foot dystonia. The interval from injury to development of dystonia ranged from 24 hours to three years.

In some patients, oromandibular dystonia has appeared after dental treatment. ${ }^{315}$ Brin and colleagues ${ }^{16}$ briefly reported 23 patients in whom trauma precipitated dystonia in the injured region after an interval of between one day and eight weeks. Jankovic and Van Der Linden, ${ }^{17}$ also described a number of patients with dystonia and tremor induced by peripheral trauma; of 28 cases, 13 had persistent dystonia (four of a hand, five of a foot, one of an arm, one of a leg and two of craniocervical musculature) developing within one day to 12 months after a relevant injury. In blepharospasm, a history of preceding local ocular disease has been recorded in about $12 \%$ of cases. $^{18}$

Despite these numerous reports linking dystonia and peripheral injury, the data should 
be interpreted with caution. Recall bias is probable in some cases, and the history may be misleading; for example, injuries may be attributable to the onset of dystonia, such as falling due to a dystonic foot posture, as seemed likely in cases 25 and 26. Moreover, a direct cause and effect relationship cannot be assumed. Trauma is very frequent in the general population; if injuries alone cause dystonia it should be much more prevalent than it is. We are not proposing that trauma is more common in patients with dystonia. In addition to this study, we have compared the frequency of trauma in 72 patients with ITD in the year before onset with that in an equal number of healthy age and sex matched controls over the same period. There was no significant difference in the incidence of trauma between cases and controls (Fletcher, Harding and Marsden, unpublished observations). Consequently, an interaction between trauma and pre-existing liability, rather than injury alone, is the most probable mechanisms by which trauma could be involved in the development of ITD.

The pre-existing liability in cases where trauma might have triggered dystonia is highly likely to be genetic, particularly in patients with generalised disease. It is now clear that inheritance of segmental and generalised ITD is autosomal dominant in both Jewish and nonJewish families in the $\mathrm{UK},{ }^{2}$ in Jewish families in Israel $^{19}$ and in Jewish and non-Jewish families in the United States. ${ }^{20}{ }^{21}$ The reduced penetrance and striking intrafamilial variation in phenotype suggest that environmental factors can modify the expression of the ITD gene. ${ }^{2}$ Peripheral trauma may be such an environmental factor in view of the frequency with which injuries appear to precipitate or exacerbate the symptoms of ITD. Seventeen patients in this study (over 16\%) gave a history suggesting trauma induced dystonia. Involuntary movements developed at the same site as the injury, which was not trivial, and within one year; dystonia later became more widespread (see table). It is interesting that eight of these 17 patients had affected relatives and were therefore genetically at risk for the development of ITD before the injury. Biased ascertainment in favour of familial cases is not the explanation for this, as patients referred specifically because of a positive family history were excluded from this study. ${ }^{2}$ Familial cases among patients with trauma induced dystonia were also mentioned by Brin and colleagues (nine of 23) ${ }^{16}$ and Jankovic and Van Der Linden (three of 13). ${ }^{17}$ This is consistent with the hypothesis that peripheral injury might precipitate dystonia in ITD gene carriers.

The precise mechanism by which trauma might precipitate dystonia can only be speculative while the pathophysiology of ITD remains obscure. Some authors have emphasised severe pain, sometimes with sympathetic algodystrophy or Sudeck's atrophy, after injuries which have led to dystonia. ${ }^{10}$ Schot ${ }^{13}$ suggested that alterations in spinal dopaminergic systems or other complex central pain pathways may be involved in such cases. ${ }^{22}$

A major termination of the spinothalamic tract is in the thalamus ${ }^{23}$ where the ventrobasal nucleus, which projects to the somatosensory cortex, has the clearest role in pain transmission. This system probably subserves discriminative pain perception ${ }^{24}$ while the spino-reticular pathway may be involved in large scale somatic and autonomic responses to pain. ${ }^{25}$ The main projection of the nocioceptive component of the spinoreticular tract is to the nucleus gigantocellularis (NGC) in which (in the rat) nearly all cells respond to noxious stimuli. ${ }^{26}$ NGC neurons project principally to the nuclei centrum medianum and parafascicularis (CM-PF nuclei) which are a major source of thalamic projections to the striatum, the thalamostriatal tract. ${ }^{2428}$ Anatomically, this pathway could allow central pain pathways to influence basal ganglia function.

There is also direct experimental evidence that peripheral injury alters basal ganglia chemistry. De Ceballos et $a l^{29}$ found that a thermal injury to one hind limb in the rat causes early ( 24 hours) bilateral reduction of leu-encephalin immunoreactivity in the globus pallidus, and later (one week) bilateral (but most marked contralateral), reduction of both met-encephalin and leu-encephalin immunoreactivity in globus pallidus, and of metencephalin in caudate-putamen. These late changes in basal ganglia encephalin content could conceivably be responsible for peripheral trauma precipitating dystonia in genetically susceptible individuals.

Of particular interest is the association of peripheral injury, reflex sympathetic dystrophy and dystonia. ${ }^{12}$ Recently, Schwartzman and Kerrigan $^{30}$ reviewed 43 patients with reflex sympathetic dystrophy and major movement disorders, which in 33 took the form of obvious dystonia. A number of mechanisms has been invoked to explain the clinical features of reflex sympathetic dystrophy. Peripheral mechanisms alone (such as ectopic generation of neuronal impulses with ephaptic cross-talk at the site of injury, as well as sympatheticallymediated alteration in mechanoreceptor and nocioceptive responses), seem unlikely to be responsible. It is possible that reorganisation of spinal cord sensory networks occurs to explain, for example, the spread of pain in the condition. Whatever causes such changes in spinal cord sensory activity could also affect spinal motor machinery. ${ }^{30}$

Whatever the mechanism responsible for trauma associated dystonia, there are practical implications. In previously reported cases ${ }^{3}$ and in six patients in this series, the injury implicated in the onset of exacerbation of dystonia was a surgical or dental procedure. While treatment of incidental illnesses may involve unavoidable surgery, and some injuries are inevitable in everyday life, it may be that caution is appropriate when considering surgical treatment for dystonia, particularly orthopaedic procedures to which many patients are subjected with unpredictable benefits.

We thank the neurologists and general practitioners who kindly allowed us to study their patients, as well as the patients for their cooperation. Financial support from the Medical Research Council is gratefully acknowledged. 
1 Marsden CD, Harrison MJG. Idiopathic torsion dystonia (dystonia musculorum deformans). A review of 42 patients. Brain 1974;97:793-810.

2 Fletcher NA, Harding AE, Marsden CD. A genetic study of idiopathic torsion dystonia in the UK. Brain 1990 113:379-95.

3 Koller WC, Wong GF, Lang A. Post-traumatic movement disorders: a review. Movement Disorders 1989;4 20-36.

4 Brett EM, Hoare RD, Sheehy MP, Marsden CD. Progressive hemidystonia due to focal basal ganglia lesion after mild head trauma. J Neurol Neurosurg Psychiatry 1981; 44:460.

5 Fahn S, Marsden CD, Calne DB. Classification and investigation of dystonia. In: Marsden CD, Fahn S, eds. Movement Disorders 2. London: Butterworths, 1987: 332-58.

6 Andrew J, Fowler C, Harrison MJG. Hemidystonia due to focal basal ganglia lesion after head injury and improved focal basal ganglia lesion after head injury and improved by stereotaxic thalamotomy

7 Gowers WR. A manual of diseases of the nervous system, vol 2. London: Churchill, 1888:659.

8 Wilson SAK. Neurology, 2nd ed, vol 3. London: Butterworths, 1955:1966.

9 Sheehy MP, Marsden CD. Trauma and pain in spasmodic torticollis. Lancet 1980;i:777-8.

10 Sheehy MP, Marsden CD. Writer's cramp-a focal dystonia. Brain 1982;105:461-80.

11 Sheehy MP, Rothwell JC, Marsden CD. Writer's cramp. In: Fahn S, Marsden CD, Calne DB, eds Dystonia 2 . Advances in Neurology, vol 50. New York: Raven Press, Advances in Neu

12 Marsden CD, Obeso JA, Traub MM, Rothwell JC, Kranz H, La Cruza F. Muscle spasms associated with Sudeck's $\mathrm{H}, \mathrm{La}$ Cruza F. Muscle spasms associated with
atrophy after injury. $B M J 1984 ; 288: 173-6$.

13 Schott GD. The relationship of peripheral trauma and pain to dystonia. J Neurol Neurosurg Psychiatry 1985;48

14 Schott GD. Induction of involuntary movements by peripheral trauma. An analogy with causalgia. Lancet 1986; ii: $712-15$.

15 Thompson PD, Obeso JA, DelGado G, Gallego G, Marsden $\mathrm{CD}$. Focal dystonia of the jaw and differential diagnosis of unilateral jaw and masticatory spasm. $J$ Neurol Neurosurg Psychiatry 1986;49:651-6.
16 Brin MF, Fahn S, Bressman SB, Burke RE. Dystonia precipitated by peripheral trauma. Neurology 1986; 36(suppl 1):119.

17 Jankovic J, Van Der Linden C. Dystonia and tremor induced by peripheral trauma: predisposing factors. J Neurol Neurosurg Psychiatry 1988;51:1512-19.

18 Grandas F, Elston J, Quinn N, Marsden CD. Blepharospasm: a review of 264 patients. J Neurol Neurosurg Psychiatry 1988;51:767-72

19 Zilber N, Korczyn AD, Kahana E, Fried K, Alter M Inheritance of idiopathic torsion dystonia among Jews. J Med Genetics 1984;21:13-20.

20 Zeman W, Kaebling R, Pasamanick B. Idiopathic dystonia musculorum deformans I. The hereditary pattern. $A m$ Human Genetics 1959;11:188-202.

21 Bressman SB, de Leon D, Brin MF, et al. Idiopathic torsion dystonia among Ashkenazi Jews: Evidence for autosomal dystonia among Ashe. Ann Neurol 1989;26:612-20.

22 Rothwell JC, Obeso JA. The anatomical and physiological basis of torsion dystonia. In: Marsden CD, Fahn S, eds. basis of torsion dystonia. In: Marsden CD, Fahn S, eds. Movement

23 Fields HL, ed. Introduction to Pain Syndromes in Neurology. London: Butterworths, 1990:1-18.

24 Guillbaud G, Peschanski M, Besson J-M. Experimental data related to nocioception and pain at the supraspinal level. In: Wall PD, Malzack R, eds. A textbook of pain. London Churchill Livingstone, 1984:110-18.

25 Willis WD. The origin and destination of pathways involved in pain transmission. In: Wall PD, Melzack R, eds. $A$ textbook of pain. London: Churchill Livingstone, 1984: 88-99.

26 Benjamin RM. Single neurons in the rat medulla responsive to nocioceptive stimulation. Brain Research 1970;24: 525-9.

27 Marsden CD. The mysterious motor functions of the basal ganglia: the Robert Wartenberg Lecture. Neurology 1982:

28 Brodal A. Neurological anatomy in relation to clinical medicine. Oxford: Oxford University Press, 1981

29 De Ceballos ML, Baker M, Rose J, Jenner P, Marsden CD Do encephalins in basal ganglia mediate a physiological motor rest mechanism? Movement Disorders 1986;1: 223-33.

30 Schwartzman RJ, Kerrigan J. The movement disorder of reflex sympathetic dystrophy. Neurology 1990;40:57-61. 